This is a preprint of a chapter that has been published by Springer Protocols in 2018 in the book Brain Morphometry edited by Gianfranco Spalletta, Fabrizio Piras and Tommaso Gili.

\title{
Morphometry and Development: Changes in Brain Structure from Birth to
}

\section{Adult Age}

Running head: Morphometry and Development

Christian K. Tamnes ${ }^{1}$ and Ylva Østby ${ }^{1,2}$

${ }^{1}$ Department of Psychology, University of Oslo, Oslo, Norway

${ }^{2}$ National Centre for Epilepsy, Oslo University Hospital, Oslo, Norway

Corresponding author: Christian K. Tamnes, Department of Psychology, University of Oslo, PO Box 1094 Blindern, 0317 Oslo, Norway; Email: c.k.tamnes@psykologi.uio.no 


\begin{abstract}
This chapter gives an overview of the field of brain morphometry and development from birth to adult age, including selected methodological considerations and fields of application. Brain development is an area of research where morphometry studies have greatly increased our knowledge, revealing organized patterns where regional differences in cortical, subcortical and white matter structural maturation play a role for cognitive development. Studies show that early rapid increases in grey matter structures are generally followed by decreases, whereas white matter continues to increase throughout childhood and adolescence. The chapter also highlights the importance of developmental perspectives in structural neuroimaging studies for our understanding of clinical conditions such as schizophrenia, autism spectrum disorders and epilepsy.
\end{abstract}

Keywords: Adolescence, Autism spectrum disorder, Brain structure, Childhood, Cognition, Epilepsy, Infancy, Maturation, MRI, Schizophrenia 


\section{Introduction}

Genes, maturation and experience continuously interact to shape who we are, the brain, and our cognitive abilities at any point in time. Knowledge of human brain development was initially based in large part on post-mortem studies and histological studies (examination of tissue under the microscope). While such studies provide invaluable information regarding the basic processes underlying brain development, they are unable to inform us fully about how different brain structures change over time within and between individuals and how these changes relate to behavioural and cognitive changes. Over the last couple of decades, however, the use of neuroimaging techniques, especially magnetic resonance imaging (MRI), has given us a much better understanding of how the brain changes during development [1] as well as throughout life [2].

Structural MRI provides high quality, detailed images of brain anatomy. Using sophisticated analysis software, we can perform quantitative measurements of a range of different aspects of brain morphology for different types of brain tissue; grey matter, which includes both cerebral cortex and a number of subcortical structures, and white matter, as well as for specific structures and regions. Morphometry, measurements of form, including size and shape, has been used to study both age-related differences across individuals (cross-sectional studies) and developmental changes by following the same individuals over time (longitudinal studies). The earliest longitudinal structural MRI project originated at the Child Psychiatry Branch of the National Institute of Mental Health [3]. Other MRI techniques can be used to examine e.g. microstructural properties of fibre tracts in the brain (diffusion tensor imaging, DTI), brain activity during the performance of various tasks (functional MRI, fMRI) and intrinsic activity patterns in brain networks (resting state fMRI: rs-fMRI). Together, these techniques have provided new and exciting insights into the extensive and complex changes that occur in the brain from birth to adult age.

Studying brain development is a window into understanding characteristic features of child and adolescent behaviour [4,5], psychological and cognitive development [6], as well as emerging sex differences and the possible role of puberty-related hormonal changes, which differ dramatically for girls and boys [7,8]. Also, many mental illnesses have their onset in adolescence or early adulthood and the developing adolescent brain might, in combination 
with new social demands and stressors in this period of life, partly explain that $[9,10]$.

This chapter will in section two begin with a brief discussion of a few selected methodological considerations that are of particular relevance for neuroimaging studies of brain development. For broader and more in-depth coverage of such issues, we refer the reader elsewhere [1,11]. Section three will give an overview of typical development of brain morphology in infancy and throughout childhood and adolescence, and how this relates to lifespan changes. We will also introduce some factors influencing individual differences in brain development. Section four will focus on atypical development of brain morphology in selected clinical populations and discuss the relationship between typical and atypical brain development from a dimensional perspective. Finally, section five will consider the behavioural and cognitive relevance of structural brain development.

\section{Methodological Considerations for Studies of Brain Development}

To date there have been few studies of typical brain development in infancy and almost none that investigate the period between infancy and school age. The main reason for this is that young children are more likely to move while inside the MRI scanner, which results in lower image quality. While anaesthesia is an option in clinical examinations, it is generally not used in research involving volunteers. MRI examinations of infants can be performed during natural sleep after feeding, but scanning of young children is more challenging and studies of this age group are therefore particularly rare. Planning and preparation using instructional videos and mock-scanner visits, and friendly scanning operators can however help to alleviate the anxieties of young participants and improve image quality. It is sometimes also helpful to let young participants come to the scanner facilities a few days prior to their appointment, to see it for themselves. That way, there is less pressure mixed with apprehension on the day of their scan.

Quality control procedures, both pre- and post-processing, are of great importance in brain morphometry studies to reduce noise in the data and guard against spurious findings. In the context of development, this was clearly shown in a new study by Ducharme and colleagues [12]. Their results showed that post-processing quality control, in the form of exclusion of scans defined as quality control failures on the basis of visual inspection and review of extreme values, had a large impact on identified developmental trajectories for cortical 
thickness from mid-childhood to early adulthood, with a shift toward more complex trajectories when including scans of lower quality. An image quality issue of particular importance is motion-related artefacts, which may greatly affect results in all types of imaging studies, especially in studies of development. It is reasonable to assume that such artefacts are more common in younger participants and thus can be confounded with age or time-point effects. While this issue has received increasing attention in fMRI studies in the past few year, structural MRI studies would also benefit greatly from an increased focus on quantitative motion detection and measurement, as well as increased use of both prospective and retrospective motion compensation procedures, and the inclusion of such procedures in commonly used software packages $[13,14]$.

Other conceptual and methodological considerations that are of importance for developmental brain morphometric studies, discussed further elsewhere [1], include the use of appropriate terminology when describing results from cross-sectional studies (e.g. to refer to "age-related differences"), the modelling of non-linear longitudinal data and the interpretation of the resulting trajectories [15], and whether and how to correct for global quantities, such as the intracranial volume or the total brain size measures, which might also change during development [16]. Studies of infants and young children have additional major challenges, including image registration, use of atlases, which are often based on adult brains, the large scale of anatomical changes, and the change of image intensity contrasts [11]. Despite these methodological issues, great advances in the understanding of normal brain development have resulted from brain morphometric studies.

\section{Typical Development of Brain Morphology}

\subsection{Brain Development in Infancy}

We now know that the brain and our cognitive abilities change continuously throughout our lives. Nevertheless, some periods of life are marked by larger and more extensive changes in the brain than others, typically the periods early and late in life: development and aging. Furthermore, it is clear that the development of the brain that occurs prior to birth (prenatal) and during the first few years of life (postnatal) qualitatively and quantitatively far exceeds the changes seen in the rest of the life cycle. With careful preparation, it is often possible to perform high-quality MRI studies of infants that provide invaluable information on early brain development. While the majority of our neurons are present at birth, the brain also 
continues to develop very rapidly after birth. Neuronal processes (axons and dendrites) mature and the density of contact points (synapses) between neurons increases, axons undergo myelination and those that are already myelinated get increased thickness of their insulating myelin sheaths.

The extremely rapid changes in brain morphology in early infancy were recently mapped in a longitudinal MRI study, which examined a large group of new-borns aged 2 to 90 days old [17]. The results showed that the brain's total volume increased by approximately one percent per day in the period immediately after birth (Fig. 1). In a series of studies in infants, John H. Gilmore and colleagues have shown how brain structures undergo major changes during the first two years of life, reflecting the enormous psychological and behavioural development seen in this period. For example, they found that the volume of cerebral cortex more than doubled $(+108 \%)$ during the first year of life and showed a further, but markedly smaller, increase $(+18 \%)$ in the second year [18]. To put these huge changes in perspective, we know that the cerebral cortex of elderly patients with Alzheimer's disease decreases by one to three percent, dependent on region, per year [19].

\subsection{Brain Development in Childhood and Adolescence}

As discussed above, there are scarcely any brain imaging studies of the age period between infancy and school age. This is primarily because it is challenging to perform high-quality MRI examinations of participants in this age-range due to movement. However, we know that the brain continues to develop throughout childhood and adolescence via processes including further myelination and elimination of synapses [1]. In common with the prenatal overproduction and elimination of neurons, after birth we see an initial overproduction of synapses followed by an extensive pruning, which in certain areas of cortex probably continues well into the teens. These processes contribute to increasing efficiency and further specialisation of information processing, at the expense of the possibility for change.

Interestingly, the human brain seems to undergo a slow and especially protracted development compared to other species. For example, myelination of the human brain continues beyond adolescence, whereas degree of myelination in the chimpanzee brain reaches adult levels at roughly the same time as the animal become sexually mature [20]. Much of the potential and many of the vulnerabilities - of our brains will depend on this prolonged maturation and experiences. 
MRI studies of children and adolescents show that early increases in the volume of cortex and subcortical structures are followed by reductions, whereas white matter continues to increase in volume [16,21]. Morphometric changes in the brain from late childhood to adulthood are thus tissue specific: the amount of white matter increases, whereas that of grey matter decreases (Fig. 2). Unfortunately, our knowledge about the underlying neurobiological processes largely rely upon extrapolation from very limited post-mortem material and from data acquired in other species and both of these approaches have limitations. The post-mortem material is rare, there is concern that these brains are not representative of healthy brains and we obviously cannot do longitudinal studies. With data from other species, we cannot be sure that the processes are the same or happened at the same rate as in humans. Nonetheless, it is generally thought that both grey matter decreases and white matter increases observed in morphometric studies, from late childhood to adulthood, are partly caused by increasing calibre and myelination of axons [22-24], which also involves sub- and intracortical myelination and white matter encroachment into the lower cortical layers. The grey matter reductions can partly also be explained by regressive changes in the form of simplification or elimination of neuronal processes and synapses and associated processes [25-27].

In addition to measures such as cortical volume and density, it is clear that more specific and distinct components of cortical morphology, thickness and surface area (and also other morphometric features [28,29]), in many contexts should be investigated separately, as these are influenced by different evolutionary [30], genetic [31], and cellular [32] processes. In the first two years of life, both cortical thickness and surface area increase over time [33], but from mid-childhood to adulthood, these distinct components show very different developmental patterns. Available data suggest a monotonic decline for cortical thickness, albeit faster at younger ages, while surface area increases until early adolescence and then slightly decreases [34-37], and both measures show decreases across the adult lifespan [38].

Importantly, neurodevelopmental processes in childhood and adolescence occur to differing degrees and at different times in different parts of the brain. Brain development is thus characterized by marked regional differences. A number of studies have described sequences of development of various brain regions. In the cerebral cortex [39,40] and for white matter fibre tracts [21,41], development appears to generally follow a posterior-anterior pattern, with relatively late development of prefrontal brain regions (Fig. 3) and connections. Regional developmental patterns are also clearly seen in the heterogeneous changes in subcortical grey 
matter volumes (Fig. 4). In particular, the medial temporal lobe structures, hippocampus and amygdala, appear to follow different developmental patterns across adolescence than the basal ganglia structures, with the former showing volume increases or little or no change and the latter showing volume decreases in most studies [42-45].

The brain has a modular organization - delimited regions have specific functions. Examples include the role of visual cortex in visual perception, and that of the hippocampus in certain forms of memory. Despite this specialization, a single brain region is never solely responsible for a specific function - even a relatively 'simple' task such as recognizing a family member or a friend requires communication between a large number of dispersed brain regions. Brain development therefore involves maturation of circuits and entire systems - and the development of different regions must be organized and coordinated. It has for instance recently been found that the rates of developmental change in different cortical regions are organized with respect to one another [46]. The results of this study showed that the degree to which change in any one region was coordinated with the change in other regions varied systematically. The rate of change in areas of association cortex in the frontal and temporal lobes showed the strongest correlations with change in other cortical areas, whereas the pace of development of primary sensory and motor areas was less closely related to development in the rest of the cortex. It was speculated that this might be because association areas in the frontal and temporal lobes are particularly important for integrative cognitive processes that require a high degree of functional coordination with other brain regions. Another recent study showed coordinated patterns of cortical-subcortical change within known neurocognitive systems [47]. Specifically, development of the hippocampus was related mainly to development of the temporal lobe, while development of basal ganglia was related to development of frontal, insular and cingulate cortices. Several other organization systems have also been proposed, including functional [40], cytoarchitectonic [48], topographic [49], evolutionary [50-52], genetic [36] and network-based [53,54], and these systems likely coexist, but possibly have different roles for different structural parameters [55]. Although brain development is characterized by regional differences, diverse changes take place in a carefully organized and coordinated fashion.

\subsection{Lifespan Perspectives}

When does the human brain stop developing? And do we enter a phase of complete stability after adolescence? Neuroimaging studies clearly show that it is not possible to specify an age 
when development stops or when aging begins, and that it is not the case that the brain is static at any age, but rather that it is characterized by life-long experience-dependent neurocognitive plasticity. Although a certain degree of stability can be seen in adulthood relative to the earlier development, there does not appear to be any period of life in which brain structure and function remain fixed. The brain continues to change throughout life, with positive and negative processes presumably occurring alongside one another as we grow older [56]. Interestingly, there is increasing recognition of how early life influences on brain and cognition can affect the whole lifespan and of how neurocognitive changes in different periods of life may be related. For instance, recent studies provide evidence supporting the hypothesis that normal brain degeneration in aging in some respects, mirrors brain development $[39,57]$.

\subsection{Individual Difference in Brain Development}

There is great individual variability in brain structure at any given age and in brain development. And as for most aspects of a child's development, the development of the brain is the result of longitudinally ongoing and interrelated influence (transactions) between multiple endogenous (internal) and exogenous (external) factors [58]. Here, we will briefly discuss how some selected factors can affect individual differences in brain morphology and development in children and adolescents. Specifically, we will discuss heritability, as well as how early nutrition, substance use, the mental status of pregnant women and birth related factors could affect children's structural brain development.

Twin studies have found substantial heritability estimates not just for the volume of specific brain structure, cortical thickness and surface area in adults [31], but also for developmental changes in these aspects of brain morphology in childhood and adolescence $[43,59]$. So far, we have limited knowledge about the role of specific genes. But recently reported results suggest that polymorphisms in several putative risk genes for mental illnesses or dementias may have similar effects on brain structure early in life as in adult age [60], suggesting that the influences of these genes may represent stable life-long effects. An increasing number of neuroimaging studies also show that influences from the environment both prenatally and in infancy can have effects on later brain structure. Women's nutrition during pregnancy is critical for the initial development of the central nervous system of the foetus, and may, together with the infant's early diet, also have effects on later brain structure and development [61]. And it is well established that women's use of a range of different substances during 
pregnancy, including alcohol, tobacco, cocaine, methamphetamine, marihuana, opioids, can have long-lasting negative effects on the brain of the foetus [62,63]. Intriguingly, pregnant women's mental health and emotional state may also possibly have long-term, although much more subtle, effects on the brain of the foetus. For instance, a recent study showed weak, but relatively consistent negative associations between maternal depressive symptoms at 19, 25, and 31 weeks' gestation and cortical thickness in children when aged 6-9 years old [64].

Early influences such as those briefly discussed above may also influence birth related (perinatal) factors, which in turn may have consequences for the child's further development. It is for instance well established that prenatal stress can cause lower birthweight for gestational age and earlier delivery [65], and we know that these factors, on a group level, are associated with a range of adverse neurodevelopmental outcomes for the children. While it has long been known that premature delivery and low birth weight, typically defined as less than $2.500 \mathrm{~g}$, can influence brain development, it has now also been shown that normal variation in birth weight is positively associated with cortical surface area in several regions and brain volumes many years later $[66,67]$.

In addition to the importance of genetic factors and the long-lasting and in some cases possibly life-long effects of early environmental influences on brain morphology, it is also important to remember that the brain, in interaction with the physical, social and cultural environment, continues to change throughout life. A large number of animal studies, both studies comparing animals reared in so-called enriched environments with animals in standard experimental environments and studies comparing animals in the wild and in captivity, have documented a range of different neural changes in response to complex stimulation and experiences [68]. In humans, an increasing number of controlled training studies, both with adults and with young participants, support the conclusion that experiences and learning can have substantial influences on brain structure [69,70]. This general conclusion is further supported by naturalistic studies of early negative experiences, e.g. neglect, abuse, and stress $[71,72]$. A particularly interesting study compared brain structure in a relatively large sample of young adolescents who were internationally adopted from institutional care of variable quality as young children to a comparison group reared with their biological families [73]. The results showed smaller volume of frontal cortical regions, driven primarily by differences in cortical surface area, in post-institutionalized youth, and also that longer duration of institutional care was associated with smaller hippocampal volumes. It should be stressed that 
such effects generally are subtle and that the causal relationships between early negative experiences and later brain structure likely are complex and may also involve multiple other factors. Further investigations, both controlled experiments and naturalistic studies, are needed to examine if and how the potential for change in brain structure as a result of experiences and learning differ quantitatively and/or qualitatively with age.

\section{Atypical Development of Brain Morphology}

\subsection{Brain Development in Clinical Populations}

For many research groups, a strong motivation for studying typical development has been to eventually identify and understand development when it has gone awry. It is essential to know what is normal to be able to say what is abnormal or pathological. Below, we will briefly discuss schizophrenia, autism spectrum disorder and epilepsy as examples of clinical populations where aspects of brain morphology may show atypical development.

MRI studies of children and adolescents with early-onset schizophrenia overall implicate similar brain regions as those delineated in adult samples, including, but not limited to, prefrontal, medial temporal and superior temporal regions [74,75]. It is however not known whether the brain abnormalities are more or less severe than those observed in adult-onset schizophrenia. Of great interest, studies of brain structure in children and adolescents with schizophrenia also indicate altered developmental trajectories of grey matter volumes and regional cortical thickness [76,77]. Moreover, a recent study found high spatial overlap between a widespread network of mainly transmodal grey matter regions, which show prolonged development during adolescence and regions showing atypical development in adolescents with schizophrenia [57]. This might indicate that the pattern of brain structure alterations in schizophrenia is influenced and to some extent determined by the timing of the pathological processes in relation to typical brain development patterns.

Group-level variations in brain morphology have also been found to be associated with autism spectrum disorder, and these appear to change across the lifespan so that case-control differences e.g. in young children may differ from those observed in other stages of life [78]. Early brain development in autism spectrum disorder seems to be characterised by accelerated volume increases, but less is known about the development during adolescence. New 
longitudinal studies do however suggest accelerated developmental decreases in regional brain volumes and cortical thickness across adolescence [79-81].

Two cases of epilepsy syndromes illustrate how developmental perspectives may inform us of pathological brain functioning, in these cases in the form of epileptic seizures and decreased cognitive functioning. In juvenile myoclonic epilepsy (JME), seizures in the form of myoclonic jerks and generalized tonic-clonic seizures appear during adolescence or young adulthood. The seizures originate in frontal networks, bilaterally, and the syndrome is often accompanied by mild executive dysfunction. Several voxel-based morphometry-studies have shown increased grey matter volume or cortical thickness associated with this syndrome, possibly suggesting a deficit in the cortical thinning process $[82,83]$. This may help explain the adolescent onset of the disorder. However, another study actually found decreased cortical thickness in similar brain regions [84]. Yet another study, using measures of thickness, surface area and curvature from FreeSurfer analyses, found evidence of cortical morphology abnormalities indicating early onset disruption in cortical folding [85]. As no studies have followed the developmental trajectory of cortical thickness or curvature in new-onset JME, it remains to be seen whether there is an element of early onset developmental abnormality, a developmental deficit in cortical pruning, or atrophy related to the seizure activity. A developmental perspective is therefore paramount.

A related problem in the field of epilepsy is temporal lobe epilepsy (TLE) and the question of progressive disease or developmental vulnerability. TLE often presents during adolescence or early adulthood, but may arise at almost any age (rarely in old age, though). For a subgroup of patients, antiepileptic treatment is unsuccessful, leading to chronic TLE, sometimes with epilepsy surgery as a last resort treatment. One hypothesis is that TLE follows a progressively deteriorating course with increased hippocampal sclerosis and seizure frequency, evident as presenting with more serious memory deficits in middle aged to older patient groups [86]. A cross-sectional cortical thickness study of TLE patients aged 14-60 years showed subtle widespread brain morphometric alterations compared to controls, i.e. alterations not limited to the temporal lobes [87]. The study also suggested a rather fixed discrepancy between the patient group and the controls throughout the studied age span, although ventricular size was increasing with age to a greater degree in patients than in controls. A developmental origin has been proposed by Helmstaedter and Elger [88], based on a cross-sectional study of memory function in TLE patients aged 6-68 years. They noted an early point at which the 
trajectory of memory performance in the TLE group diverged from the controls, then keeping a steady distance to the controls throughout the rest of the studied age span. This could indicate a developmental disturbance in brain development that ultimately may lead to TLE and memory dysfunction. A developmental perspective and the use of brain morphometric methods are needed to find this out.

Importantly, it should be stressed that further longitudinal research is generally needed to establish whether and how brain developmental trajectories are altered in different specific disorders. In the case of schizophrenia for instance, popular models suggest that abnormal neurodevelopmental processes [89,90] and brain connectivity [91] play pivotal roles, but although DTI studies of white matter microstructure consistently find lower regional fractional anisotropy (FA) in children and adolescents with early-onset schizophrenia compared with healthy control participants, only three studies have investigated case-control developmental differences and the results are highly mixed [92]. One study concluded that adolescents with schizophrenia and controls show diverging white matter developmental trajectories, a second study concluded with converging trajectories and a recent study found parallel trajectories.

\subsection{Dimensional Perspectives}

An important question is whether the traits that underlie pathology are always unique to disease states. New evidence suggests that this is not the case: often it is not a matter of categorical distinctions, but of variation along continuous dimensions. This has been clearly demonstrated in studies of children with diagnosed attention deficit hyperactivity disorder (ADHD) and children with subclinical ADHD symptoms. First, it has been found that maturation of the cerebral cortex is delayed in children with an ADHD diagnosis compared with a control group, especially in frontal areas [93]. Next, the same research group showed that degree of hyperactivity and impulsivity in typically developing healthy children was also associated with the rate of cortical development in some of the same cortical regions [94]. Similar results have been obtained for conduct disorder and related subclinical symptoms. While some studies indicate that children diagnosed with conduct disorder have reduced grey matter volume in specific brain regions, including prefrontal cortices [95], a recent study found that also symptoms of conduct problems within the normal range was associated with thinner left hemisphere prefrontal and supramarginal cortices [96]. Results such as these suggest that abnormal cortical development in certain brain regions is characteristic of both 
ADHD and 'normal' hyperactivity and impulsivity, as well as conduct disorder and minor symptoms of behavioural problems, just to differing degrees in each case. The findings therefore suggest that there may be neuroanatomical continuity between subclinical symptoms and at least certain clinical disorders.

For psychosis spectrum disorders, there is initial evidence, from studies of individuals at increased risk for developing such disorders, either individuals with diagnosed relatives (genetic high-risk) or individuals showing specific symptoms or functional decline (clinical high-risk), that structural and microstructural brain changes might precede the disorder [97,98]. However, in both these cases, a large proportion of these individuals will likely not develop clinical-level psychotic disorders, and these findings, together with studies of population-based samples [99], support a dimensional perspective also on the brain morphology phenotypes associated with psychosis spectrum disorders and psychotic experiences (see also [100]).

\section{Behavioral and Cognitive Relevance of Brain Development}

Developmental differences across brain regions are relatively consistent with behavioural studies, which show for example rapid development of visual acuity and perception in the first year of life. More complex functions, such as the abilities to plan and to inhibit responses, which are dependent on regions including prefrontal cortices, develop over a longer period extending well into the teens. Brain regions involved in more basic abilities and skills thus appear to develop earlier than those supporting more complex cognition. However, there is a major need for longitudinal studies that directly examine the relationship between brain development and cognitive development, as only a few studies exist. In fact, in the light of the increasing number of studies examining brain-behaviour relationship in various clinical conditions, there are surprisingly few studies documenting such links in typically developing children and adolescents. It is important to establish these principles in normal development, in order to make a framework for understanding abnormal development. A reason for the lack of studies could be related to the methodological issues mentioned earlier. In addition, associations between changes in brain morphometric variables and changes in behavioural measures are likely quite subtle. Thus, a large study population is needed, as well as time and patience. 
As histological studies have shown, the neuronal processes and synapses in the cerebral cortex are gradually pruned and this likely contributes, together with associated changes and a range of other processes, to making the cortex thinner as development progresses. A natural assumption then is that cognitive functions, as they also improve with increasing age, are related to cortical reduction and thinning. In line with this, studies show moderate associations between age-related or longitudinal cortical volume reductions or thinning and improvements in general intellectual abilities [101], memory [102], and working memory and executive functioning [103-105].

The heterogeneity of brain development is not only seen in grey matter structures. As previously mentioned, white matter tracts also undergo refinement during childhood and adolescence. This refinement, through processes such as increased myelination and alignment of axon fibres, is important for increasing speed and consistency of signal transmission necessary for network communication. An integration of morphometric and DTI studies is needed for understanding the dynamic interplay between these developmental processes in underlying cognitive development. In one such study, we investigated the simultaneous contribution of cortical thinning and developing white matter tract microstructure on the development of working memory [105]. We found unique effects of morphometric and DTI measures on digit span performance in children and adolescents. Furthermore, the effects varied dynamically during development, with white matter measures having the largest effect during early/middle adolescence and cortical thickness having the largest effect during late adolescence. To speculate, this might for instance mean that the integrity of the whole network during development is first dependent on the development of the communicating white matter tracts.

In a prospective multimodal imaging study of normal development, Ullman et al. [106] investigated the correlations between DTI, grey matter volume/density and functional MRI activation, on the one hand, and measures of working memory on the other hand. As expected, there were cross-sectional relationships between frontal and parietal cortical regions and visuospatial working memory performance. However, even more interestingly, when they used the MRI-derived variables to predict working memory performance as measured 2 years later, a new pattern emerged. Here, functional MRI and DTI in and around thalamus and the caudate nucleus best predicted future performance, even when current performance on the same task was included in the regression model. Morphometric measures also predicted future 
performance when entered by itself in a regression model; however, when entered together with the other two modalities of MRI data, morphometry did not remain statistically significant. The authors speculate that a network including thalamus and caudate might be especially involved in working memory training, facilitating developmental improvement as well. This study shows that multimodal imaging and longitudinal research designs have great potential for revealing new insight into brain development and development of cognition and behaviour. As brain imaging acquisition and analysis methods become increasingly sensitive to new aspects of brain morphology and function, the diversity of developmental processes may be mapped in greater detail.

\section{Conclusion}

Morphometry studies have documented that although the most dramatic developmental changes in brain morphology take place before birth and during the first few years of life, the human brain also continues to undergo substantial structural remodeling throughout childhood and adolescence, and into adulthood. Different tissue classes, brain regions and structural features develop differently, and there are large inter-individual differences in brain morphology at any given age and in its development. Available data suggest that aspects of structural brain development may be altered in certain clinical conditions, including schizophrenia spectrum disorders, autism spectrum disorder and epilepsy, but also neuroanatomical continuity between subclinical symptoms and certain clinical disorders. Developmental perspectives may shed new light on the natural course of clinical disorders and subclinical symptoms. Morphometric studies, especially in combination with other neuroimaging modalities, are currently our best tool for capturing the complex and multifaceted nature of brain development in healthy children and adolescents, although special care must be taken regarding methodological challenges when studying children.

Acknowledgements: This work was supported by the Research Council of Norway and the University of Oslo (to CKT) and the South-Eastern Norway Regional Health Authority (to YØ).

\section{References}

1 Mills KL, Tamnes CK (2014) Methods and considerations for longitudinal structural brain imaging analysis across development. Dev Cogn Neurosci 9:172-90. 
Hedman AM, van Haren NE, Schnack HG, Kahn RS, Hulshoff Pol HE (2012) Human brain changes across the life span: a review of 56 longitudinal magnetic resonance imaging studies. Hum Brain Mapp 33:1987-2002.

3 Giedd JN, Raznahan A, Alexander-Bloch A, Schmitt E, Gogtay N, Rapoport JL (2015) Child psychiatry branch of the National Institute of Mental Health longitudinal structural magnetic resonance imaging study of human brain development. Neuropsychopharmacology 40:43-49.

4 Blakemore SJ, Mills KL (2014) Is adolescence a sensitive period for sociocultural processing? Annu Rev Psychol 65:187-207.

5 Crone EA, Dahl RE (2012) Understanding adolescence as a period of social-affective engagement and goal flexibility. Nat Rev Neurosci 13:636-650.

6 Walhovd KB, Tamnes CK, Fjell AM (2014) Brain structural maturation and the foundations of cognitive behavioral development. Curr Opin Neurol 27:176-184.

7 Blakemore SJ, Burnett S, Dahl RE (2010) The role of puberty in the developing adolescent brain. Hum Brain Mapp 31:926-933.

8 Peper JS, Dahl RE (2013) Surging hormones: Brain-behavior interactions during puberty. Curr Dir Psychol Sci 22:134-139.

9 Paus T, Keshavan M, Giedd JN (2008) Why do many psychiatric disorders emerge during adolescence? Nat Rev Neurosci 9:947-957.

10 Keshavan MS, Giedd J, Lau JY, Lewis DA, Paus T (2014) Changes in the adolescent brain and the pathophysiology of psychotic disorders. Lancet Psychiatry 1:549-558.

11 Sled JG, Nossin-Manor R (2013) Quantitative MRI for studying neonatal brain development. Neuroradiology 55 Suppl 2:97-104.

12 Ducharme S, Albaugh MD, Nguyen TV, Hudziak JJ, Mateos-Perez JM, Labbe A, Evans AC, Karama S, Brain Development Cooperative Group (2016) Trajectories of cortical thickness maturation in normal brain development - The importance of quality control procedures. NeuroImage 125:267-279.

13 Yendiki A, Koldewyn K, Kakunoori S, Kanwisher N, Fischl B (2013) Spurious group differences due to head motion in a diffusion MRI study. NeuroImage 88C:79-90.

14 Brown TT, Kuperman JM, Erhart M, White NS, Roddey JC, Shankaranarayanan A, Han ET, Rettmann D, Dale AM (2010) Prospective motion correction of highresolution magnetic resonance imaging data in children. NeuroImage 53:139-145.

15 Fjell AM, Walhovd KB, Westlye LT, Østby Y, Tamnes CK, Jernigan TL, Gamst A, Dale AM (2010) When does brain aging accelerate? Dangers of quadratic fits in crosssectional studies. NeuroImage 50:1376-1383.

16 Mills KL, Goddings AL, Herting MM, Meuwese R, Blakemore SJ, Crone EA, Dahl RE, Guroglu B, Raznahan A, Sowell ER, Tamnes CK (2016) Structural brain development between childhood and adulthood: Convergence across four longitudinal samples. NeuroImage 141:273-281.

17 Holland D, Chang L, Ernst TM, Curran M, Buchthal SD, Alicata D, Skranes J, Johansen H, Hernandez A, Yamakawa R, Kuperman JM, Dale AM (2014) Structural growth trajectories and rates of change in the first 3 months of infant brain development. JAMA Neurol 71:1266-1274.

18 Gilmore JH, Shi F, Woolson SL, Knickmeyer RC, Short SJ, Lin W, Zhu H, Hamer RM, Styner M, Shen D (2012) Longitudinal development of cortical and subcortical gray matter from birth to 2 years. Cereb Cortex 22:2478-2485.

19 Fjell AM, Walhovd KB, Fennema-Notestine C, McEvoy LK, Hagler DJ, Holland D, Brewer JB, Dale AM (2009) One-year brain atrophy evident in healthy aging. J Neurosci 29:15223-15231. 
20 Miller DJ, Duka T, Stimpson CD, Schapiro SJ, Baze WB, McArthur MJ, Fobbs AJ, Sousa AM, Sestan N, Wildman DE, Lipovich L, Kuzawa CW, Hof PR, Sherwood CC (2012) Prolonged myelination in human neocortical evolution. Proc Natl Acad Sci U S A 109:16480-16485.

21 Lebel C, Beaulieu C (2011) Longitudinal development of human brain wiring continues from childhood into adulthood. J Neurosci 31:10937-10947.

22 Benes FM (1989) Myelination of cortical-hippocampal relays during late adolescence. Schizophr Bull 15:585-593.

23 Benes FM, Turtle M, Khan Y, Farol P (1994) Myelination of a key relay zone in the hippocampal formation occurs in the human brain during childhood, adolescence, and adulthood. Arch Gen Psychiatry 51:477-484.

24 Yakovlev PA, Lecours IR: The myelogenetic cycles of regional maturation of the brain; in Minkowski A (eds): Regional development of the brain in early life. Oxford, Blackwell, 1967, pp

25 Bourgeois JP, Rakic P (1993) Changes of synaptic density in the primary visual cortex of the macaque monkey from fetal to adult stage. J Neurosci 13:2801-2820.

26 Huttenlocher PR, Dabholkar AS (1997) Regional differences in synaptogenesis in human cerebral cortex. J Comp Neurol 387:167-178.

27 Petanjek Z, Judas M, Simic G, Rasin MR, Uylings HB, Rakic P, Kostovic I (2011) Extraordinary neoteny of synaptic spines in the human prefrontal cortex. Proc Natl Acad Sci U S A 108:13281-13286.

28 Aleman-Gomez Y, Janssen J, Schnack H, Balaban E, Pina-Camacho L, AlfaroAlmagro F, Castro-Fornieles J, Otero S, Baeza I, Moreno D, Bargallo N, Parellada M, Arango C, Desco M (2013) The human cerebral cortex flattens during adolescence. J Neurosci 33:15004-15010.

29 Mutlu AK, Schneider M, Debbane M, Badoud D, Eliez S, Schaer M (2013) Sex differences in thickness, and folding developments throughout the cortex. NeuroImage 82:200-207.

30 Geschwind DH, Rakic P (2013) Cortical evolution: judge the brain by its cover. Neuron 80:633-647.

31 Kremen WS, Fennema-Notestine C, Eyler LT, Panizzon MS, Chen CH, Franz CE, Lyons MJ, Thompson WK, Dale AM (2013) Genetics of brain structure: contributions from the Vietnam Era Twin Study of Aging. Am J Med Genet B Neuropsychiatr Genet 162B:751-61.

32 Chenn A, Walsh CA (2002) Regulation of cerebral cortical size by control of cell cycle exit in neural precursors. Science 297:365-569.

33 Lyall AE, Shi F, Geng X, Woolson S, Li G, Wang L, Hamer RM, Shen D, Gilmore JH (2015) Dynamic development of regional cortical thickness and surface area in early childhood. Cereb Cortex 25:2204-2212.

34 Tamnes CK, Herting MM, Goddings AL, Meuwese R, Blakemore SJ, Dahl RE, Güroğlu B, Raznahan A, Sowell ER, Crone EA, Mills KL (In press) Development of the cerebral cortex across adolescence: A multisample study of interrelated longitudinal changes in cortical volume, surface area and thickness. J Neurosci

35 Wierenga LM, Langen M, Oranje B, Durston S (2014) Unique developmental trajectories of cortical thickness and surface area. NeuroImage 87:120-126.

36 Fjell AM, Grydeland H, Krogsrud SK, Amlien I, Rohani DA, Ferschmann L, Storsve AB, Tamnes CK, Sala-Llonch R, Due-Tønnessen P, Bjornerud A, Sølsnes AE, Håberg AK, Skranes J, Bartsch H, Chen CH, Thompson WK, Panizzon MS, Kremen WS, Dale AM, Walhovd KB (2015) Development and aging of cortical thickness correspond to genetic organization patterns. Proc Natl Acad Sci U S A 112:15462-7. 
37 Vijayakumar N, Allen NB, Youssef G, Dennison M, Yucel M, Simmons JG, Whittle S (2016) Brain development during adolescence: A mixed-longitudinal investigation of cortical thickness, surface area, and volume. Hum Brain Mapp 37:2027-2038.

38 Storsve AB, Fjell AM, Tamnes CK, Westlye LT, Øverbye K, Aasland HW, Walhovd KB (2014) Differential longitudinal changes in cortical thickness, surface area and volume across the adult life span: regions of accelerating and decelerating change. $\mathrm{J}$ Neurosci 34:8488-8498.

39 Tamnes CK, Walhovd KB, Dale AM, Østby Y, Grydeland H, Richardson G, Westlye LT, Roddey JC, Hagler DJ, Jr., Due-Tønnessen P, Holland D, Fjell AM, Alzheimer's Disease Neuroimaging Initiative (2013) Brain development and aging: overlapping and unique patterns of change. NeuroImage 68:63-74.

40 Gogtay N, Giedd JN, Lusk L, Hayashi KM, Greenstein D, Vaituzis AC, Nugent TF, 3rd, Herman DH, Clasen LS, Toga AW, Rapoport JL, Thompson PM (2004) Dynamic mapping of human cortical development during childhood through early adulthood. Proc Natl Acad Sci U S A 101:8174-8179.

41 Westlye LT, Walhovd KB, Dale AM, Bjørnerud A, Due-Tønnessen P, Engvig A, Grydeland H, Tamnes CK, Østby Y, Fjell AM (2010) Life-span changes of the human brain white matter: diffusion tensor imaging (DTI) and volumetry. Cereb Cortex 20:2055-2068.

42 Østby Y, Tamnes CK, Fjell AM, Westlye LT, Due-Tønnessen P, Walhovd KB (2009) Heterogeneity in subcortical brain development: A structural magnetic resonance imaging study of brain maturation from 8 to 30 years. J Neurosci 29:11772-11782.

43 Swagerman SC, Brouwer RM, de Geus EJ, Hulshoff Pol HE, Boomsma DI (2014) Development and heritability of subcortical brain volumes at ages 9 and 12. Genes Brain Behav 13:733-742.

44 Goddings AL, Mills KL, Clasen LS, Giedd JN, Viner RM, Blakemore SJ (2014) The influence of puberty on subcortical brain development. NeuroImage 88:242-251.

45 Dennison M, Whittle S, Yucel M, Vijayakumar N, Kline A, Simmons J, Allen NB (2013) Mapping subcortical brain maturation during adolescence: evidence of hemisphere- and sex-specific longitudinal changes. Dev Sci 16:772-791.

46 Raznahan A, Lerch JP, Lee N, Greenstein D, Wallace GL, Stockman M, Clasen L, Shaw PW, Giedd JN (2011) Patterns of coordinated anatomical change in human cortical development: a longitudinal neuroimaging study of maturational coupling. Neuron 72:873-884.

47 Walhovd KB, Tamnes CK, Bjørnerud A, Due-Tønnessen P, Holland D, Dale AM, Fjell AM (2015) Maturation of cortico-subcortical structural networks - Segregation and overlap of medial temporal and fronto-striatal systems in development. Cereb Cortex 25:1835-1841.

48 Shaw P, Kabani NJ, Lerch JP, Eckstrand K, Lenroot R, Gogtay N, Greenstein D, Clasen L, Evans A, Rapoport JL, Giedd JN, Wise SP (2008) Neurodevelopmental trajectories of the human cerebral cortex. J Neurosci 28:3586-3594.

49 Vandekar SN, Shinohara RT, Raznahan A, Roalf DR, Ross M, DeLeo N, Ruparel K, Verma R, Wolf DH, Gur RC, Gur RE, Satterthwaite TD (2015) Topologically dissociable patterns of development of the human cerebral cortex. J Neurosci 35:599609.

50 Amlien IK, Fjell AM, Tamnes CK, Grydeland H, Krogsrud SK, Chaplin TA, Rosa MG, Walhovd KB (2016) Organizing principles of human cortical development thickness and area from 4 to 30 years: Insights from comparative primate neuroanatomy. Cereb Cortex 26:257-267. 
51 Hill J, Inder T, Neil J, Dierker D, Harwell J, Van Essen D (2010) Similar patterns of cortical expansion during human development and evolution. Proc Natl Acad Sci U S A 107:13135-13140.

52 Fjell AM, Westlye LT, Amlien I, Tamnes CK, Grydeland H, Engvig A, Espeseth T, Reinvang I, Lundervold AJ, Lundervold A, Walhovd KB (2015) High-expanding cortical regions in human development and evolution are related to higher intellectual abilities. Cereb Cortex 25:26-34.

53 Alexander-Bloch A, Giedd JN, Bullmore E (2013) Imaging structural co-variance between human brain regions. Nat Rev Neurosci 14:322-336.

54 Alexander-Bloch A, Raznahan A, Bullmore E, Giedd J (2013) The convergence of maturational change and structural covariance in human cortical networks. J Neurosci 33:2889-2899.

55 Krongold M, Cooper C, Bray S (In press) Modular development of cortical gray matter across childhood and adolescence. Cereb Cortex

56 Lindenberger U (2014) Human cognitive aging: corriger la fortune? Science 346:572578.

57 Douaud G, Groves AR, Tamnes CK, Westlye LT, Duff EP, Engvig A, Walhovd KB, James A, Gass A, Monsch AU, Matthews PM, Fjell AM, Smith SM, Johansen-Berg H (2014) A common brain network links development, aging, and vulnerability to disease. Proc Natl Acad Sci U S A 111:17648-17653.

58 Sameroff A (2010) A unified theory of development: a dialectic integration of nature and nurture. Child Dev 81:6-22.

59 van Soelen IL, Brouwer RM, van Baal GC, Schnack HG, Peper JS, Collins DL, Evans AC, Kahn RS, Boomsma DI, Hulshoff Pol HE (2012) Genetic influences on thinning of the cerebral cortex during development. NeuroImage 59:3871-3880.

60 Knickmeyer RC, Wang J, Zhu H, Geng X, Woolson S, Hamer RM, Konneker T, Lin W, Styner M, Gilmore JH (2014) Common variants in psychiatric risk genes predict brain structure at birth. Cereb Cortex 24:1230-1246.

61 Isaacs EB (2013) Neuroimaging, a new tool for investigating the effects of early diet on cognitive and brain development. Front Hum Neurosci 7:445.

62 Derauf C, Kekatpure M, Neyzi N, Lester B, Kosofsky B (2009) Neuroimaging of children following prenatal drug exposure. Semin Cell Dev Biol 20:441-454.

63 Roussotte F, Soderberg L, Sowell E (2010) Structural, metabolic, and functional brain abnormalities as a result of prenatal exposure to drugs of abuse: evidence from neuroimaging. Neuropsychol Rev 20:376-397.

64 Sandman CA, Buss C, Head K, Davis EP (2015) Fetal exposure to maternal depressive symptoms is associated with cortical thickness in late childhood. Biol Psychiatry 77:324-334.

65 Glover V (2014) Maternal depression, anxiety and stress during pregnancy and child outcome; what needs to be done. Best Pract Res Clin Obstet Gynaecol 28:25-35.

66 Walhovd KB, Fjell AM, Brown TT, Kuperman JM, Chung Y, Hagler DJ, Jr., Roddey JC, Erhart M, McCabe C, Akshoomoff N, Amaral DG, Bloss CS, Libiger O, Schork NJ, Darst BF, Casey BJ, Chang L, Ernst TM, Frazier J, Gruen JR, Kaufmann WE, Murray SS, van Zijl P, Mostofsky S, Dale AM, Pediatric Imaging Neurocognition Genetics Study (2012) Long-term influence of normal variation in neonatal characteristics on human brain development. Proc Natl Acad Sci U S A 109:20089-94.

67 Raznahan A, Greenstein D, Lee NR, Clasen LS, Giedd JN (2012) Prenatal growth in humans and postnatal brain maturation into late adolescence. Proc Natl Acad Sci U S A 109:11366-11371. 
68 van Praag H, Kempermann G, Gage FH (2000) Neural consequences of environmental enrichment. Nat Rev Neurosci 1:191-198.

69 Zatorre RJ, Fields RD, Johansen-Berg H (2012) Plasticity in gray and white: neuroimaging changes in brain structure during learning. Nat Neurosci 15:528-536.

70 Jolles DD, Crone EA (2012) Training the developing brain: a neurocognitive perspective. Front Hum Neurosci 6:76.

71 Lim L, Radua J, Rubia K (2014) Gray matter abnormalities in childhood maltreatment: a voxel-wise meta-analysis. Am J Psychiatry 171:854-863.

72 McCrory E, De Brito SA, Viding E (2011) The impact of childhood maltreatment: a review of neurobiological and genetic factors. Front Psychiatry 2:48.

73 Hodel AS, Hunt RH, Cowell RA, Van Den Heuvel SE, Gunnar MR, Thomas KM (2015) Duration of early adversity and structural brain development in postinstitutionalized adolescents. NeuroImage 105:112-119.

74 Brent BK, Thermenos HW, Keshavan MS, Seidman LJ (2013) Gray matter alterations in schizophrenia high-risk youth and early-onset schizophrenia: a review of structural MRI findings. Child Adolesc Psychiatr Clin N Am 22:689-714.

75 Janssen J, Aleman-Gomez Y, Schnack H, Balaban E, Pina-Camacho L, AlfaroAlmagro F, Castro-Fornieles J, Otero S, Baeza I, Moreno D, Bargallo N, Parellada M, Arango C, Desco M (2014) Cortical morphology of adolescents with bipolar disorder and with schizophrenia. Schizophr Res 158:91-99.

76 Fraguas D, Diaz-Caneja CM, Pina-Camacho L, Janssen J, Arango C (2016) Progressive brain changes in children and adolescents with early-onset psychosis: A meta-analysis of longitudinal MRI studies. Schizophr Res 173:132-139.

77 Thormodsen R, Rimol LM, Tamnes CK, Juuhl-Langseth M, Holmen A, Emblem KE, Rund BR, Agartz I (2013) Age-related cortical thickness differences in adolescents with early-onset schizophrenia compared with healthy adolescents. Psychiatry Res 214:190-196.

78 Ecker C, Bookheimer SY, Murphy DG (2015) Neuroimaging in autism spectrum disorder: brain structure and function across the lifespan. Lancet Neurol 14:1121-1134.

79 Zielinski BA, Prigge MB, Nielsen JA, Froehlich AL, Abildskov TJ, Anderson JS, Fletcher PT, Zygmunt KM, Travers BG, Lange N, Alexander AL, Bigler ED, Lainhart JE (2014) Longitudinal changes in cortical thickness in autism and typical development. Brain 137:1799-1812.

80 Lange N, Travers BG, Bigler ED, Prigge MB, Froehlich AL, Nielsen JA, Cariello AN, Zielinski BA, Anderson JS, Fletcher PT, Alexander AA, Lainhart JE (2015) Longitudinal volumetric brain changes in autism spectrum disorder ages 6-35 years. Autism Res 8:82-93.

81 Wallace GL, Eisenberg IW, Robustelli B, Dankner N, Kenworthy L, Giedd JN, Martin A (2015) Longitudinal cortical development during adolescence and young adulthood in autism spectrum disorder: increased cortical thinning but comparable surface area changes. J Am Acad Child Adolesc Psychiatry 54:464-469.

82 Cao B, Tang Y, Li J, Zhang X, Shang HF, Zhou D (2013) A meta-analysis of voxelbased morphometry studies on gray matter volume alteration in juvenile myoclonic epilepsy. Epilepsy Res 106:370-377.

83 Alhusaini S, Ronan L, Scanlon C, Whelan CD, Doherty CP, Delanty N, Fitzsimons M (2013) Regional increase of cerebral cortex thickness in juvenile myoclonic epilepsy. Epilepsia 54:e138-141.

84 Tae WS, Kim SH, Joo EY, Han SJ, Kim IY, Kim SI, Lee JM, Hong SB (2008) Cortical thickness abnormality in juvenile myoclonic epilepsy. J Neurol 255:561-566. 
85 Ronan L, Alhusaini S, Scanlon C, Doherty CP, Delanty N, Fitzsimons M (2012)

Widespread cortical morphologic changes in juvenile myoclonic epilepsy: Evidence from structural MRI. Epilepsia 53:651-658.

86 Engman E, Malmgren K: Long-term follow-up of memory in patients with epilepsy; in Zeman A, Kapur N, Jones-Gotman M (eds): Epilepsy \& Memory. Oxford Scholarship Online, 2012, pp

87 Dabbs K, Becker T, Jones J, Rutecki P, Seidenberg M, Hermann B (2012) Brain structure and aging in chronic temporal lobe epilepsy Epilepsia 53:1033-1043.

88 Helmstaedter C, Elger CE (2009) Chronic temporal lobe epilepsy: a neurodevelopmental or progressively dementing disease? Brain 132:2822-2830.

89 Rapoport JL, Giedd JN, Gogtay N (2012) Neurodevelopmental model of schizophrenia: update 2012. Mol Psychiatry 17:1228-1238.

90 Fatemi SH, Folsom TD (2009) The neurodevelopmental hypothesis of schizophrenia, revisited. Schizophr Bull 35:528-548.

91 Pettersson-Yeo W, Allen P, Benetti S, McGuire P, Mechelli A (2011) Dysconnectivity in schizophrenia: where are we now? Neurosci Biobehav Rev 35:1110-1124.

92 Tamnes CK, Agartz I (2016) White matter microstructure in early-onset schizophrenia: A systematic review of diffusion tensor imaging studies. J Am Acad Child Adolesc Psychiatry 55:269-279.

93 Shaw P, Eckstrand K, Sharp W, Blumenthal J, Lerch JP, Greenstein D, Clasen L, Evans A, Giedd J, Rapoport JL (2007) Attention-deficit/hyperactivity disorder is characterized by a delay in cortical maturation. Proc Natl Acad Sci U S A 104:1964919654.

94 Shaw P, Gilliam M, Liverpool M, Weddle C, Malek M, Sharp W, Greenstein D, Evans A, Rapoport J, Giedd J (2011) Cortical development in typically developing children with symptoms of hyperactivity and impulsivity: support for a dimensional view of attention deficit hyperactivity disorder. Am J Psychiatry 168:143-151.

95 Huebner T, Vloet TD, Marx I, Konrad K, Fink GR, Herpertz SC, Herpertz-Dahlmann B (2008) Morphometric brain abnormalities in boys with conduct disorder. J Am Acad Child Adolesc Psychiatry 47:540-547.

96 Walhovd KB, Tamnes CK, Østby Y, Due-Tønnessen P, Fjell AM (2012) Normal variation in behavioral adjustment relates to regional differences in cortical thickness in children. Eur Child Adolesc Psychiatry 21:133-140.

97 Moran ME, Hulshoff Pol H, Gogtay N (2013) A family affair: brain abnormalities in siblings of patients with schizophrenia. Brain 136:3215-3226.

98 Peters BD, Karlsgodt KH (2015) White matter development in the early stages of psychosis. Schizophr Res 161:61-69.

99 Jacobson S, Kelleher I, Harley M, Murtagh A, Clarke M, Blanchard M, Connolly C, O'Hanlon E, Garavan H, Cannon M (2010) Structural and functional brain correlates of subclinical psychotic symptoms in 11-13 year old schoolchildren. NeuroImage 49:1875-1885.

100 Satterthwaite TD, Vandekar SN, Wolf DH, Bassett DS, Ruparel K, Shehzad Z, Craddock RC, Shinohara RT, Moore TM, Gennatas ED, Jackson C, Roalf DR, Milham MP, Calkins ME, Hakonarson H, Gur RC, Gur RE (2015) Connectome-wide network analysis of youth with Psychosis-Spectrum symptoms. Mol Psychiatry 20:1508-1515.

101 Goh S, Bansal R, Xu D, Hao X, Liu J, Peterson BS (2011) Neuroanatomical correlates of intellectual ability across the life span. Dev Cogn Neurosci 1:305-312. 
102 Østby Y, Tamnes CK, Fjell AM, Walhovd KB (2012) Dissociating memory processes in the developing brain: The role of hippocampal volume and cortical thickness in recall after minutes versus days. Cereb Cortex 22:381-390.

103 Faradi N, Karama S, Burgaleta M, White MT, Evans AC, Fonov V, Collins DL, Waber DP (2015) Neuroanatomical correlates of behavioral rating versus performance measures of working memory in typically developing children and adolescents. Neuropsychologia 29:82-91.

104 Tamnes CK, Walhovd KB, Grydeland H, Holland D, Østby Y, Dale AM, Fjell AM (2013) Longitudinal working memory development is related to structural maturation of frontal and parietal cortices. J Cogn Neurosci 25:1611-1623.

105 Østby Y, Tamnes CK, Fjell AM, Walhovd KB (2011) Morphometry and connectivity of the fronto-parietal verbal working memory network in development. Neuropsychologia 49:3854-3862.

106 Ullman H, Almeida R, Klingberg T (2014) Structural maturation and brain activity predict future working memory capacity during childhood development. J Neurosci $34: 1592-1598$. 


\section{Figure}
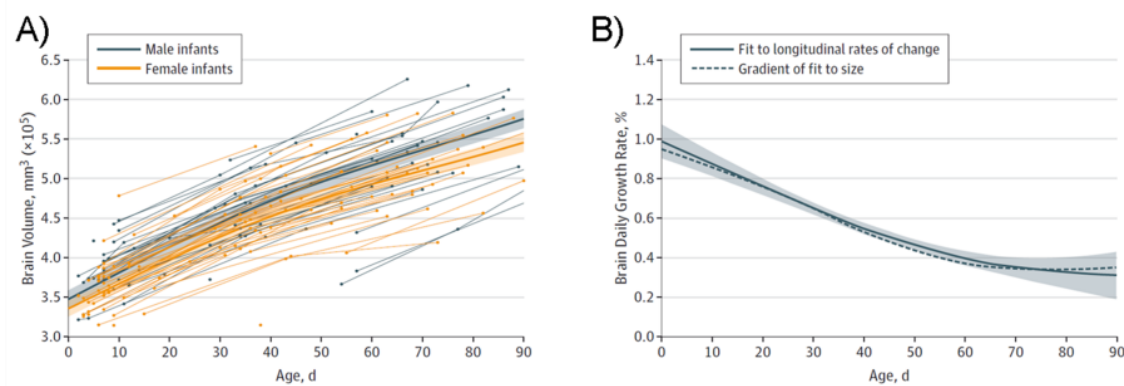

Fig. 1. Brain development in early infancy. A) Spaghetti plot showing whole-brain volume across the first 90 days after birth, along with generalized additive mixed model fits to the data, and 95\% confidence intervals. B) Daily growth rate estimates for whole-brain across the first 90 days after birth (for male and female infants combined). Reproduced from [17] with permission from American Medical Association.
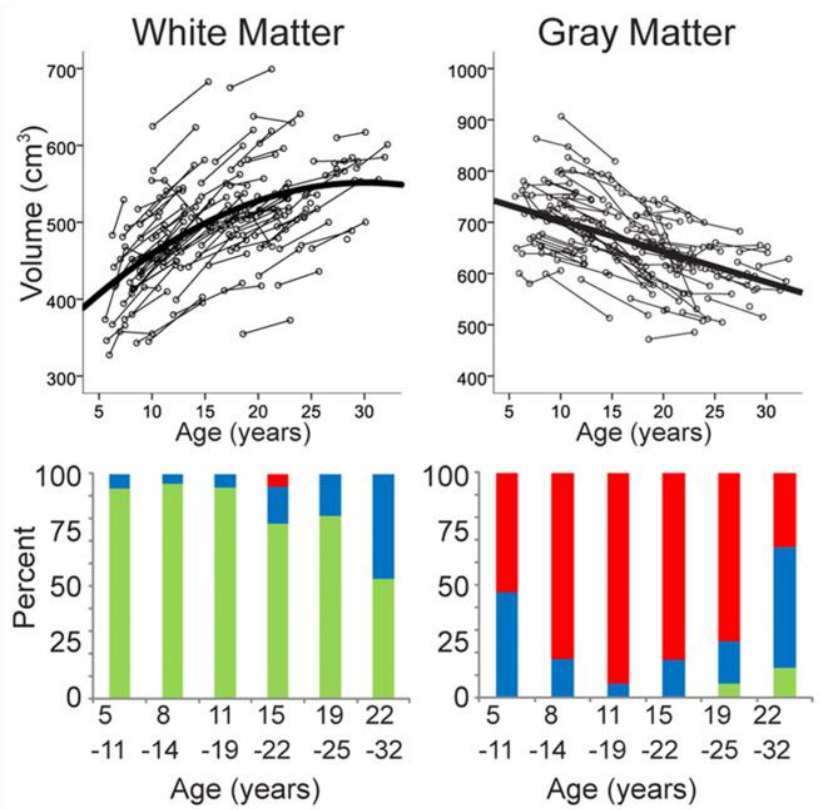

Fig. 2. Longitudinal volume changes of white matter and grey matter. Top row: Spaghetti plots of white matter volume and grey matter volume against age. Bottom row: Bar graphs reflecting the percentage of participants with volume increases (green), decreases (red), or no change (blue) within six age categories. Reproduced from [21] with permission from Society for Neuroscience. 


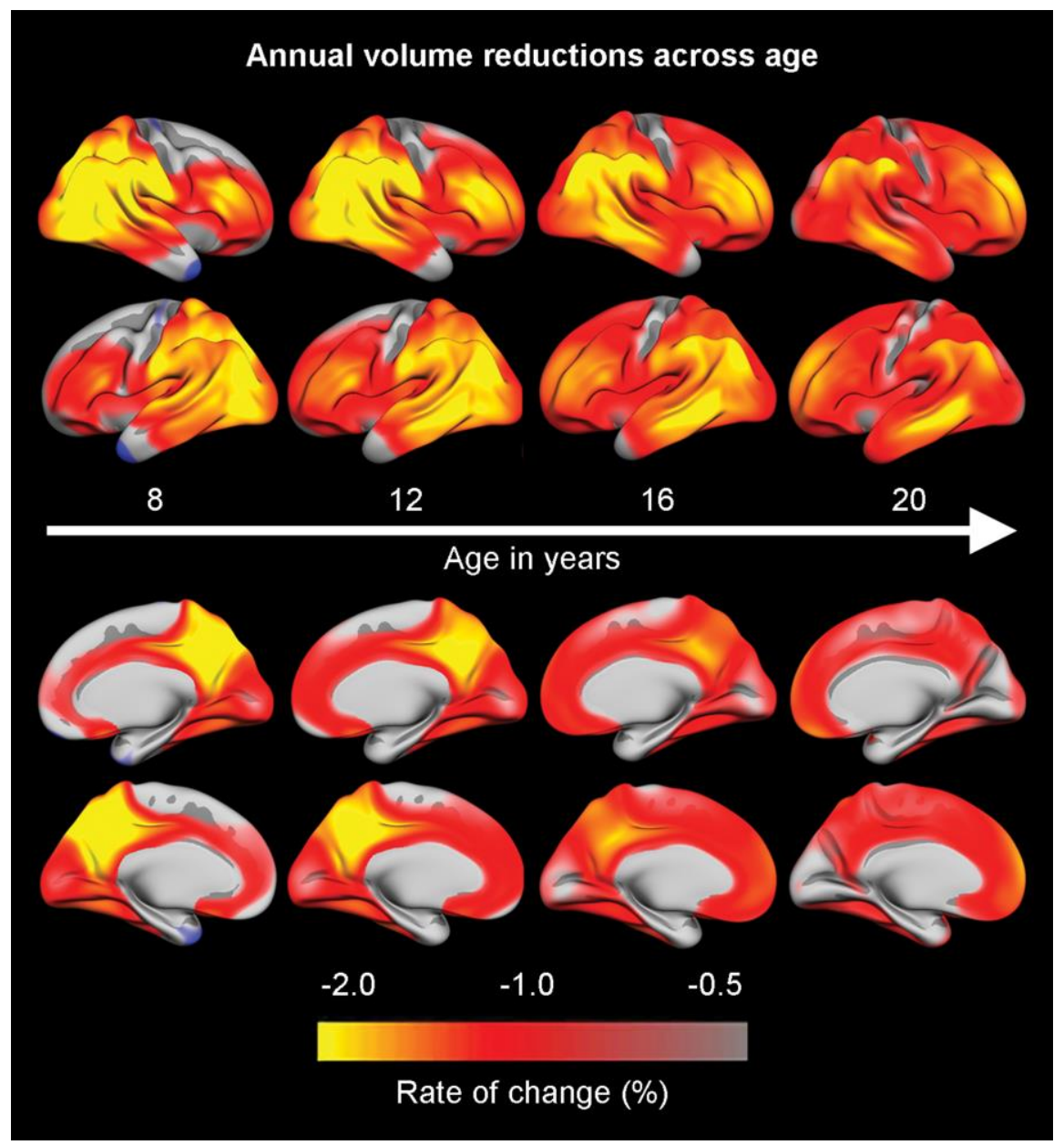

Fig. 3. Development of the cerebral cortex in childhood and adolescence. The colour scale shows annual percentage change in cortical volume. The upper two rows show the two hemispheres of the brain as seen from the side (lateral view), while the bottom two rows show the brain as seen from the middle (medial view). A sequence of development can be seen across different brain regions, with cortical development generally following a posterioranterior pattern. Modified from [39] with permission from Elsevier. 
a) Thalamus

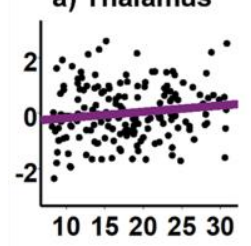

e) Brainstem

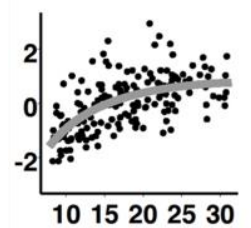

g) Caudate

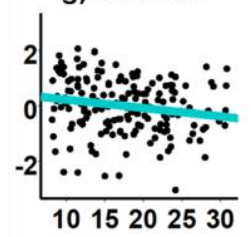

i) Accumbens

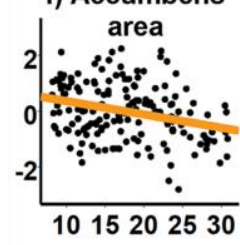

k) Amygdala

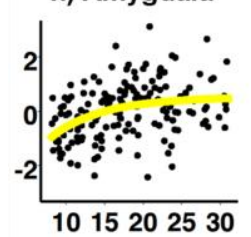

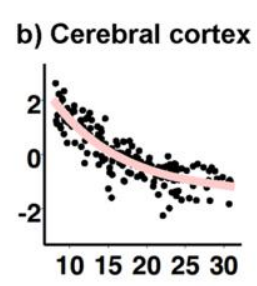
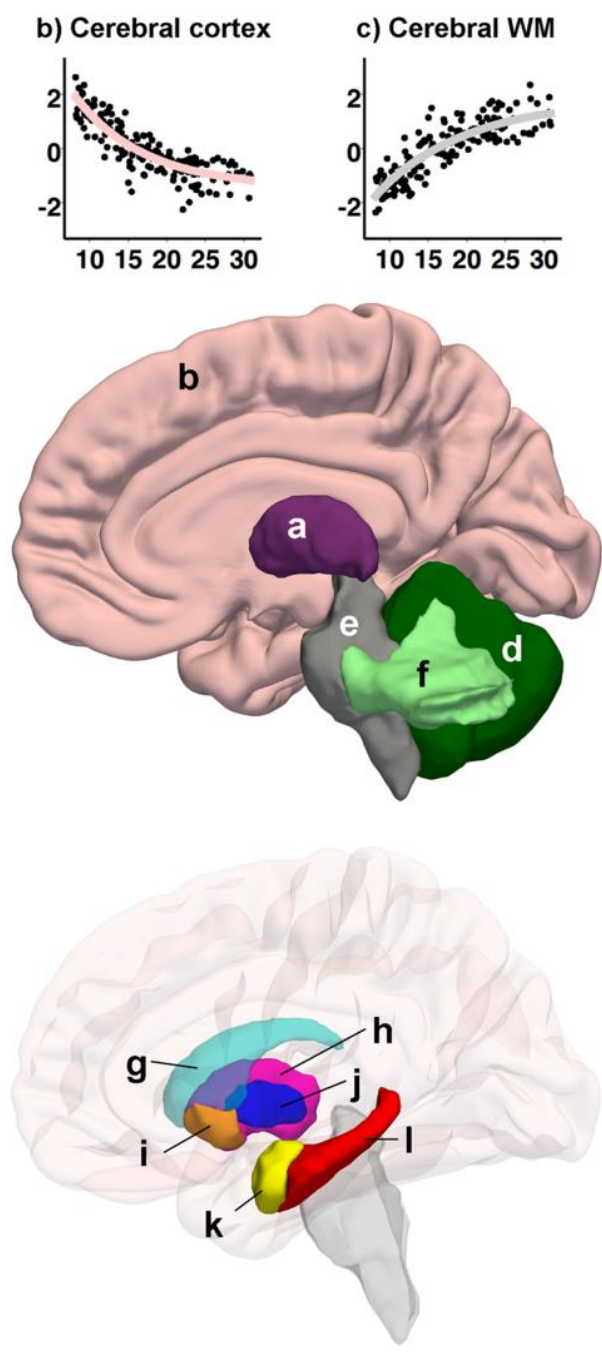

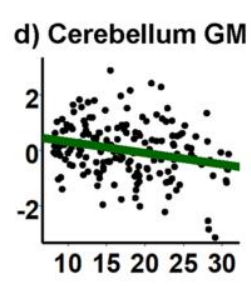

f) Cerebellum WM

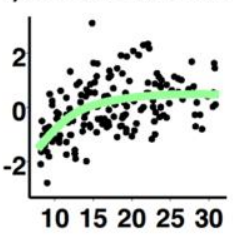

h) Putamen

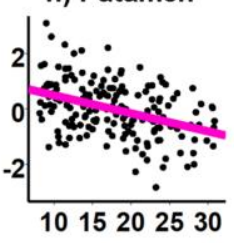

j) Pallidum

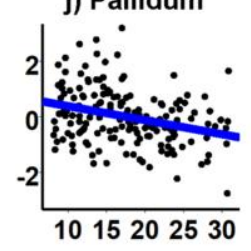

I) Hippocampus

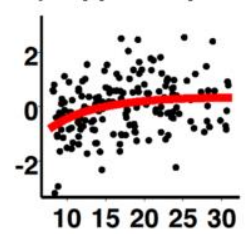

Fig. 4. Development of regional brain volumes in childhood and adolescence. Regression plots showing the relationship between age and bilateral volumes of a) thalamus, b) cerebral cortex, c) cerebral white matter, d) cerebellum grey matter, e) brainstem, f) cerebellum white matter, g) caudate, h) putamen, i) the accumbens area, j) pallidum, k) amygdala, and l) hippocampus. The volumes are corrected for total brain volume and shown in z-scores. Also displayed are samples of the segmentation (cerebral white matter not shown), based on the group mean. Reproduced from [42] with permission from Society of Neuroscience. 